
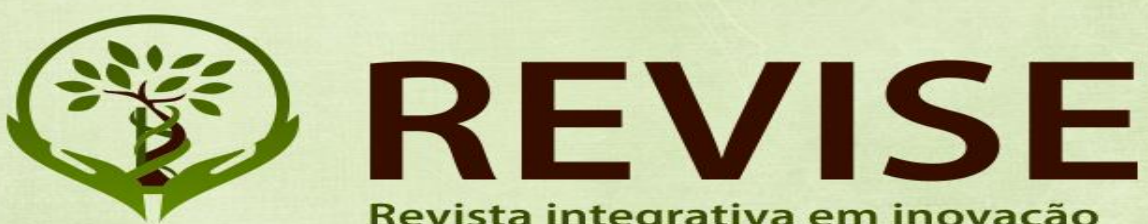

Revista integrativa em inovação tecnológica nas ciências da saúde

ISSN: 2179-6572

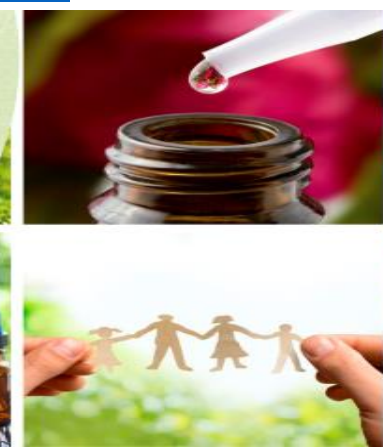

CONFERÊNCIA:

\title{
OS AVANÇOS TEÓRICOS NO ESTUDO DO DESENVOLVIMENTO HUMANO EM NOVAS PRÁTICAS INTEGRATIVAS DE SAÚDE
}

Júlio César dos Santos

UFRB

\begin{abstract}
RESUMO
O artigo registra as conferências do evento congresso internacional de inovação tecnológica nas ciências da saúde: a sustentabilidade das práticas integrativas a agroecologia, mais especificamente a conferência Os Avanços Teóricos No Estudo Do Desenvolvimento Humano em Novas Práticas Integrativas De Saúde. O estudo aponta a necessidade de novos sistemas conceituais, novas teorias e novos métodos capazes de explicar coerentemente a natureza altamente complexa dos processos de funcionamento e desenvolvimento individual que diz respeito a questão da herança, a transmissão da herança genética e cultural, a epigenética. O evento aconteceu de 15 a 18 de novembro de 2017 no IFBA SAJ sob a direção da Universidade Federal do Recôncavo da Bahia.

Palavras-chave: Processos de desenvolvimento humano. Epigenética. Herança genética. Herança cultural.
\end{abstract}

\section{ABSTRACT}

The article registers the conferences of the event International Congress on Technological Innovation in Health Sciences: the sustainability of integrative practices in agroecology, more specifically the conference Theoretical Advances in the Study of Human Development in New Integrative Health Practices. The study points to the need to new conceptual systems, new theories and new methods capable of coherently explaining the highly complex nature of the processes of individual functioning and development concerning the issue of inheritance, the transmission of genetic and cultural inheritance, epigenetics. The event took place from November 15 to 18, 2017 at IFBA SAJ under the direction of the Federal University of Recôncavo da Bahia.

Keywords: Human development processes. Epigenetics Genetic inheritance. Cultural heritage.

O desenvolvimento Humano. Revista Revise, vol. 3, no Fluxo Contínuo, p. 190-193. 


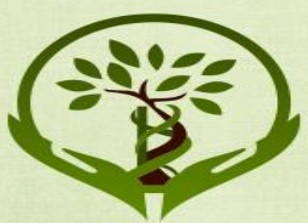

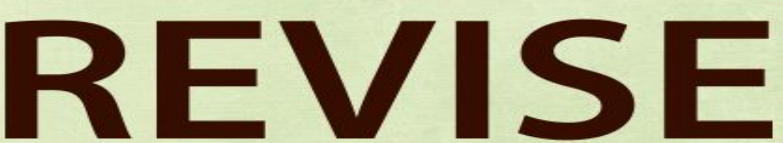

Revista integrativa em inovação tecnológica nas ciências da saúde

ISSN: 2179-6572

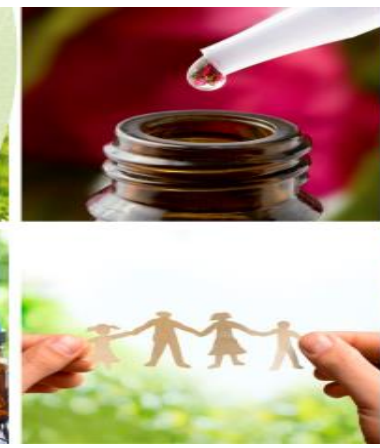

\section{CONFERÊNCIA:}

O estudo do desenvolvimento humano avançou com mudanças no campo de pesquisa e ensino, com a geração de novos dados e novas ferramentas metodológicas. Um dos focos de mudanças diz respeito à questão da herança, a transmissão da herança genética e cultural. Nos avanços da epigenética e uma compreensão mais ampla do próprio genoma fizeram a rota do genótipo ao complexo do fenótipo até o ponto em que a posição cartesiana clássica, que afirma que quem somos e o que nos tornamos a ser, é uma função aditiva simples do gene $\times$ interações ambiente tornou-se altamente insustentável. Um outro foco implica a relação de evolução e desenvolvimento ontogenético.

Esta visão da evolução está sendo rapidamente substituída por uma posição na qual o desenvolvimento ontogênico individual é entendido como parte integrante do tecido da evolução. Uma terceira questão afetada pela mudança diz respeito à cognição e ao desenvolvimento cognitivo. Para a construção teórica, a análise padrão em moldes cartesianos tinha sustentado que os processos mentais estão localizados exclusivamente no cérebro. Esta posição tem sido cada vez mais desafiadora pela perspectiva de que os processos mentais se estendem ao corpo como ação incorporada e nos mundos tecnológicos e culturais - o que sustenta cientificamente as discussões da saúde espiritual proposta no Congresso de Inovações Tecnológicas nas Ciências da Saúde: a sustentabilidade da Medicina Tradicional na Agroecologia - 2017. Outra mudança aparece na área do desenvolvimento sociocultural. Nessa área, o estudo resultou em um movimento distinto de posições que, ao mesmo tempo, identificavam desenvolvimento e cultura individual como entidades separadas e distintas, se interagindo, e em direção a uma posição de sua construção.

As mudanças de focos revolucionaram a capacidade dos cientistas de estudar a transformação de desenvolvimento nas relações entre o organismo e o contexto que constituem o processo básico de mudança intraindividual em toda a vida. Os cientistas contemporâneos do desenvolvimento se concentram em alterações sistemáticas e sucessivas no decurso dessas relações e se concentram na integração de múltiplos processos de funcionamento individual, por exemplo, cognitivos, emocionais, motivacionais; e múltiplos níveis da ecologia do desenvolvimento humano, que vão desde o ponto de vista biológico através dos níveis sociocultural e histórico, integrado à ambientes concebidos e naturais.

Os avanços científicos implicam a necessidade de novos sistemas conceituais, novas teorias e novos métodos capazes de explicar coerentemente a natureza altamente

O desenvolvimento Humano. Revista Revise, vol. 3, no Fluxo Contínuo, p. 190-193. 

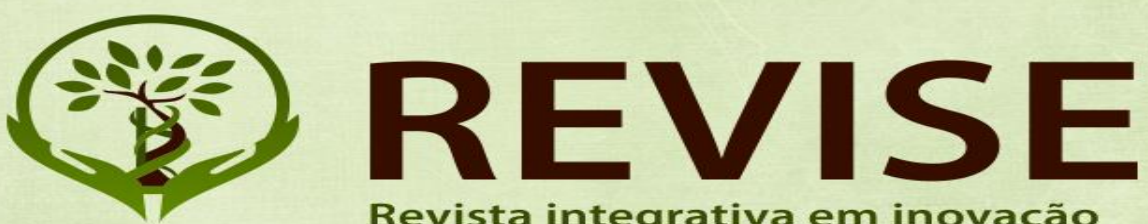

Revista integrativa em inovação tecnológica nas ciências da saúde

ISSN: 2179-6572
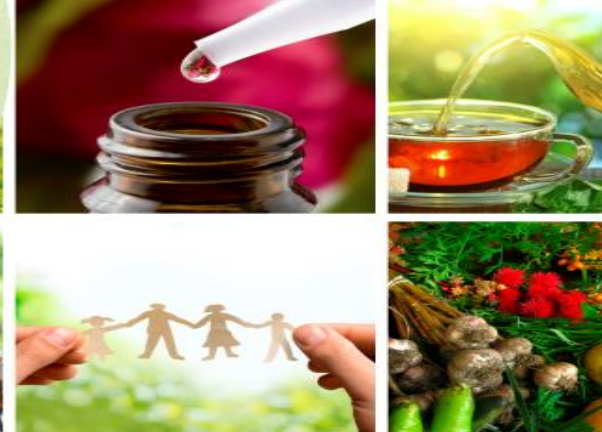

complexa dos processos de funcionamento e desenvolvimento individual. Novas teorias e métodos são enraizados em novos sistemas conceituais. Consequentemente, a vanguarda da ciência do desenvolvimento reconheceu cada vez mais as inadequações do paradigma clássico de pesquisa a abordagem Mecânica Cartesiana: as teorias e métodos. Como alternativa, a ciência do desenvolvimento tem desenvolvido novas teorias e novos métodos enraizados em um paradigma alternativo de pesquisa de processo relacional. Neste processo, o estudo do desenvolvimento de organismos vivos, incluindo os seres humanos, evoluiu a partir de um campo dominado por contradições por exemplo, explicação psicogênica ou explicação biogênica; a uma abordagem interdisciplinar da vida que reconhece o valor científico de integrar múltiplas perspectivas - biológicas, psicológicas, socioculturais, históricas - em um sistema sintético, holístico, complexo e cooperativo. As teorias e métodos do sistema de desenvolvimento relacional convertem todas essas divisões em integrações de processos de desenvolvimento, conectados relacionalmente, à medida que operam em todos os níveis de organização ao longo da vida. Assim, a ênfase conceitual de várias teorias de sistemas de desenvolvimento relacionais é colocada na natureza de relações mutuamente mutantes entre indivíduos e contextos, nas relações de contexto $\leftarrow \rightarrow$ indivíduo, o qual constitui novos desafios para as instituições de saúde atual.

$\mathrm{Na}$ prática das instituições é possível repensar os processos de desenvolvimento com novas estruturas de saúde. Assim, é possível propor a criação do núcleo de práticas integrativas com insumos agroecológicos na saúde\#educação, na abordagem relacional do desenvolvimento humano. A formação do núcleo perpassa a formação de um novo paradigma tecnológico, o paradigma da sustentabilidade que impulsiona os processos de inovação para o desenvolvimento da pessoa, sua técnica agrícola, seus meios de se manter saudáveis, sua fazenda, comunidade e sociedade.

Os pesquisadores da UFRB, vivenciam o conflito das formas de pesquisa, extensão e ensino na integralidade das áreas científicas para plantios que garanta a existência da vida ativa das pessoas: as formas de convivência integrativa do ser humano, sua cultura integrada à fauna e a flora; o respeito às sazonalidades dos alimentos constitutivos à boa saúde, a alimentação sem agrotóxicos, o manejo da água, a proteção das nascentes, o reaproveitamento das águas pluviais e fluviais; formas de reaproveitamento do lixo com tratamento aos destinos adequados. Tais elementos direcionam formas alternativas de plantio, descobertas de novos fármacos, usos no Sistema Único de Saúde, no processo educacional da clínica ampliada à comercialização de novos produtos com mais sustentabilidade, enquanto desafios às monoculturas agrícolas que implicam as áreas de saúde \# educação. 

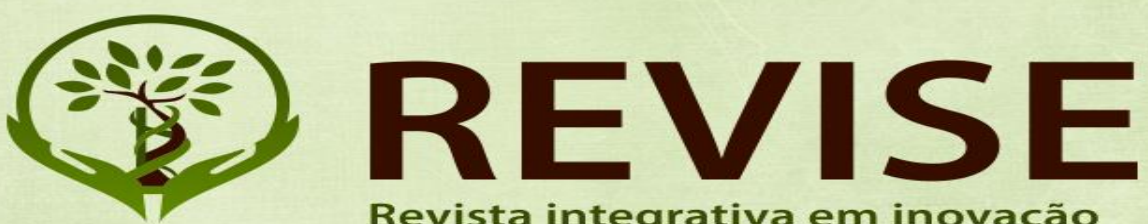

Revista integrativa em inovação tecnológica nas ciências da saúde

ISSN: 2179-6572
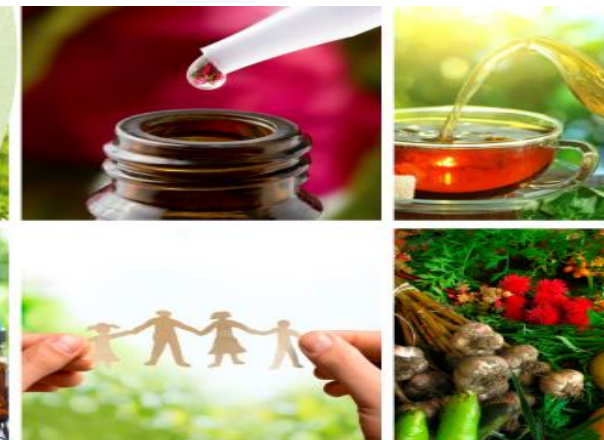

A importância em entender a relação saúde\#educação\#agronomia levou ao estudo de algumas experiências agrárias, como a redução de uso de agrotóxicos, usos de novas técnicas, as técnicas agroecológicas em alguma parte do processo de preparação, plantação e colheita. As experiências agroecológicas se aproximam das experiências em saúde com a redução de danos. Os princípios da Agronomia e da Saúde se aproximam, Agroecologia e Medicina Integrativa; são princípios que se dirigem a redução de uso de agrotóxicos, como também os de redução de danos à saúde. O foco diz respeito aos estudos da medicina tradicional que aumentam a expectativa de vida, com o uso de alimentos limpos, da agroecologia. Os princípios tecnológicos da boa saúde do homem do campo, que dizem respeito a postura na hora de trabalho quanto à adequação do seu instrumento de trabalho: desde o modo que o homem/mulher do campo pega na enxada, o formato do cabo, o tamanho do cabo, o manejo da enxada no solo; na promoção da saúde entre as horas de lazer e trabalho, como as horas de afeto com a família, como parte das horas de constituir um trabalho eficiente; os significados de ser um bom pai/boa mãe; bom marido/boa esposa. O desafio com os novos temas da pesquisa ressignificam a universidade responsiva com os conhecimentos tradicionais.

O desenvolvimento Humano. Revista Revise, vol. 3, no Fluxo Contínuo, p. 190-193. 